Transportation Research Forum

Transportation Economics: Some Developments Over the Past 30 Years

Author(s): Kenneth Button

Source: Journal of the Transportation Research Forum, Vol. 45, No. 2 (Summer 2006), pp. 7-30

Published by: Transportation Research Forum

Stable URL: http://www.trforum.org/journal

The Transportation Research Forum, founded in 1958, is an independent, nonprofit organization of transportation professionals who conduct, use, and benefit from research. Its purpose is to provide an impartial meeting ground for carriers, shippers, government officials, consultants, university researchers, suppliers, and others seeking exchange of information and ideas related to both passenger and freight transportation. More information on the Transportation Research Forum can be found on the Web at www.trforum.org. 


\title{
Transportation Economics: Some Developments Over the Past 30 Years
}

\author{
by Kenneth Button
}

This paper looks at the changes that have occurred since the 1970s in the types of economic tools used, the ways they have been used, and the impacts they have had in shaping the way we now understand transportation. Over the past 30 years, society's views on transport have changed and, with this, the issues to which we attach priority have altered. Additionally, there have been important changes in our more generic understanding of economics and this has added to the toolkit of concepts that can be applied to transport matters. The tradition of transportation economics up until the late 1960s was largely one of defining 'optimal' pricing principles in regulated markets, in understanding market domination for mergers and similar policies, and in providing advice to engineers dealing with investment decisions. There is now, however, an appreciation that providing transport services is more complex than was once thought and, therefore, it is better to leave as much as possible to market forces; but this has also happened at a time when our understanding of markets has changed. There has additionally been the emergence of novel political and governance structures, such as the Single European Market, that have resurrected older interests in such things as links between economic development and transport quality. Despite this shift to the market as a primary means of resource allocation, parallel moves have taken place to embrace more fully the external costs of environmental damage. The advent of computers, more sophisticated econometric and programming techniques, and the availability of new data sources, such as GIS, have facilitated more efficient estimation of parameters and added to the quantitative contribution of economics.

\section{INTRODUCTION}

“Only the psychologically disturbed or inadequate want transport for its own sake” (Munby 1968).

As time passes our understanding of the world increases, but the expansion of knowledge is neither evenly spread nor is it entirely objective. There is often as much change as advancement as emergent social priorities inevitably lead to selectivity in what is accepted as understanding and what is ignored or rejected. This is true of science, literature, and religion and is certainly true in economics. Many of the 'advances' in economics are simply an adoption of older theories that have been neglected or have proved inconvenient at the time. That is as true amongst economists as amongst those who want to make use of economic ideas in their public policy or business decision-making. Within this group, it also applies to those engaged in the study of the economics of transportation.

The "Economics of Transport" is a more apt title than the more oft used "Transportation Economics.” The latter seems to imply that transportation matters are somehow different and require a unique set of economic principles and tools for their analysis. In fact, the economic analysis of transportation largely makes use of a fairly well-established portfolio of economic concepts and tools. They are simply adapted to meet the challenges of the particular technical and institutional features of the sector. Further, as with virtually all areas of applied analysis, the ethos surrounding transportation economics has bent with larger forces of shifting ideas in its underlying discipline. Those looking into the economics of transportation have been selective in using new, and also rediscovered, theories that that are pertinent to their current areas of interest. They have also been instrumental in redefining these ideas to meet their particular needs and, on occasions, have added important insights that have been taken up in other branches of economics. 
Transportation Economics

That transportation is both important in economic development and is a subject of public interest seems not in doubt. At the very basic level one just has to count the column inches devoted to transportation matters in any newspaper to glean an idea of how much attention it attracts. But we still know relatively little about many of the basic economic features of the sector and certainly there emerges little consensus in public debates about its role and how to optimize its provision. At one extreme, transportation is seen as a primary lever for achieving a range of broad economic objectives, such as personal mobility, equitable regional growth, and expanding international trade, with minimal concern about its internal economic efficiency. In contrast to the "Continental" philosophy the "Anglo-Saxon" approach focuses on more neo-classical economic ideas of optimal resource allocation within the transportation industries to ensure provision of services is at minimal cost. Much of the change in the perception, and in the approach of transportation economists, over the past few decades can be traced to a larger societal shift towards the Anglo-Saxon view of policy and the need to understand transportation markets more completely.

Despite this, transportation economists still generally remain at the periphery of economics, and their area of interest is often seen as the preserve of engineering economists. Indeed, there are very few courses in transportation economics taught in economics departments; most are optional within economics departments with some offered as part of logistics programs or planning programs. Much of the literature in the field appears outside of the mainstream economics journals that are seen as important by economists and rank highly in such exercises as tenure review in the United States.

The review offered here is selective; space dictates this. ${ }^{1}$ But the selectivity, it is hoped, does not deviate from the main trends that have taken place. The material covered is largely drawn from the English language literature and, thus, tends to be more in the tradition of positive economics and the Anglo-Saxon approach to public policy as defined by Robbins (1932). Political economy and ideas developed in Continental Europe are touched upon but not given a full treatment. The coverage also takes a rather traditional view of the boundaries of transportation analysis in that much of the focus is on transportation in terms of it being a derived demand; a single direction of causality. Regional and urban economists, and more recently international trade economists, tend to treat transport as a major driver of location and of spatial patterns of economic development, as well as being influenced by these factors. Thus there are dual directions of causality. The latter analysis is unquestionably relevant and important but is not given a full treatment here. ${ }^{2}$ Similarly little is said regarding the environmental aspects of transportation and the third-party externalities associated with the movement of people and commodities despite its considerable importance and the growth of interest in the field. Space limitation is the main excuse here. ${ }^{3}$

\section{UNTIL THE LATE 1970s}

Transportation economics prior to the 1960s was heavily institutional ${ }^{4}$ and often largely descriptive. It is insightful to look at the textbooks used in the United States (e.g., early editions of Pegrum 1973 and Locklin 1972) ${ }^{5}$ and the United Kingdom in the 1950s (e.g. Bonavia 1936). This is not to say that there were not some important contributions. For example, Buchanan (1956) returned to the Pigou/Knight debate over the appropriate way to handle traffic congestion and there was the seminal volume by Beckmann et al. (1956).

Things began to change as a series of important papers and books dealing with transportation issues appeared. For example, there were the contributions of Vickery (1963 and 1969), and Walters (1961) on road pricing, Little and Mirlees (1974) on various aspects of investment analysis, notably cost-benefit analysis, of Moses and Williamson (1963) on travel time valuations, Quandt and Baumol (1966) on abstract mode analysis, and Meyer et al. (1959) on competitive issues. There were also a number of quite economically rigorous reports dealing with various aspects of transportation. Those in the United Kingdom included the Smeed Report on road pricing (UK Ministry of Transport 1964), the Commission on the Third London Airport (1971) study, the analysis of road track cost study (UK Ministry of Transport 1968), analysis of airline policy (Board of Trade 1969) and an assessment of 
railway viability (British Railways Board 1963). After 1960, the European Economic Community also became interested in economic matters as it sought to develop a Common Transport Policy. To offer support to the spread of these new ideas specialist academic journals emerged. The Journal of Transport Economics and Policy initiated in 1967 gave a specific outlet for peer reviewed papers on transport economics ${ }^{6}$ and was followed by the International Journal of Transport Economics.

The late 1960s and 1970s also saw a new breed of textbooks appear. In the United Kingdom, the initial book by Gwilliam (1964) on the economics of transportation policy was soon succeeded by Gwilliam and Mackie (1975), Thomson (1974), Heggie (1972) and Foster (1975). More specialist works were also published such as Joy (1973) on the railways. Denys Munby (1968) edited a collection of seminal, previously published papers, Harrison (1974) produced a widely used book on investment appraisal, Jones (1977) a narrower one looking at urban transportation appraisal, and Thompson and Hunter (1973) on national asset ownership. In the United States, Meyer et al. (1965), Mohring and Harwitz (1962), Friedlaender (1965), and Nelson (1964), although not strictly textbooks, were quickly adopted for more specialized graduate programs.

Institutionally, change was also taking place. In the United Kingdom, specialized centers conducting research and offering graduate programs of study in transportation economics were established, most notably at Leeds University. Other centers were established focusing on other aspects of transportation also had a significant complement of economists spread across them. The Sharp Commission provided some overall guidance to this but the centers tended to development semi autonomously under the direction of a number of strong leaders. Within government at national and local levels the advice of economists was sought and numerous studies were produced.

Much of the emphasis in the period was on what was rather narrowly called The Transportation Problem in an influential U.S. book of the period (Meyer et al. 1965), and perhaps in a way typifies the semi-capture of transportation economics at the time. The concern was with urban traffic congestion, and much of the contemporary economics may be seen as an adjunct to the dominant civil engineering paradigm of the day. There was considerable effort put into developing appropriate investment decisions mechanisms for the prioritization of highway and public transportation expansion, and for the pricing of rate-of-return regulated, and state-owned transportation modes. While economists did look at optimal institutional structures and the pricing for the use of facilities by private users, most notably motorists, this gained relatively little attention at the policy level.

\section{CHANGES IN DIRECTION, FROM THE LATE 1970s}

Economics purports to be a science in that it largely applies deductive methods. One may question this, but research is seldom neutral and is influenced by the demands of society. At the crudest level, economists react to where the market for their services is, be that private finance or government grants. This market has gone through major change over the past 30 years as society has shifted its priorities. There has also been an appreciation that some approaches to meeting established challenges have not produced the hoped for results. Thus, while the priorities may not have always shifted, the nature of the policies favored have changed quite significantly For example, the acceptance that building infrastructure to meet unrestrained demand is inefficient has led to a greater emphasis on traffic demand management. Such changes began to take place in the late 1970s.

We have already noted the shift away from the "Continental" view of the world toward the "Anglo-Saxon" philosophy where markets are allowed to allocate resources and government has more of an oversight position, intervening when it can manifestly correct market imperfections. The trend has been noticeable with the privatizations that have occurred throughout the world and across sectors, and the liberalization of regulatory regimes that have removed price controls and market entry constraints. Transportation has often been at the forefront of such changes, although the privatization of Chinese agriculture dwarfs all other policy shifts.

This trend is perhaps not surprising. John Maynard Keynes (1936, p.383) always maintained that, "The ideas of economists and political philosophers, both when they are right and when they are 
wrong, are more powerful than is commonly understood...Practical men, who believe themselves to be quite exempt from any intellectual influences, are usually the slaves of some defunct economist." Important changes in our understanding of industrial organization stemming from analysis in the 1960s and 1970s have impacted the way economists now tend to view transportation markets and the policy recommendations that have resulted for regulating these markets. Policy makers and the transportation industries have not been unaffected by these generic developments in economic thinking. ${ }^{7}$ Some of the changes seem clear in retrospect.

\section{Economic Regulation}

The way that policy makers approach the economic regulation of transport in the $21^{\text {st }}$ century is considerably different to the picture 30 years ago. In the late 1970s most transportation modes in the United Kingdom and United States were the subject of quite strict economic regulation. Regimes differed between modes, with the United States favoring private ownership with controls over entry and pricing, and the United Kingdom having a large part of its transportation industries under national, state, or local government ownership. The transport remaining in private hands was subject to market entry controls (rate controls were rare). But there was change afoot.

Advances in economic theory, or refinements to existing theories, are often the result of changing economic conditions but sometimes are independent events in themselves. What is clear is that there was a sudden up-surge of interest in microeconomics in general in the 1970s and 1980s that impacted the way transportation was viewed. In particular, new insights such as new thinking on industrial organization and public economics changed and matured. Perhaps of greatest import, however as a driver was the emergence of "supply-side economics" in the macro arena. This concentrated attention on the lack of economic efficiency at the industrial and firm level, and embraced the need for economic "deregulation."

In fact, the move to lighter interventions in transportation markets preceded the Reagan era, and goes back to the later part of the 1970s and efforts to combat the "stagflation" of the time. It is perhaps no accident that the first major industry in the United States to be deregulated was the airline industry (domestic cargo in 1977 and passengers in 1978). ${ }^{9}$ It is, for illustrative purposes, this sector that we focus on. One of the driving forces was the recognition following the earlier empirical analysis of Levine (1965), Jordon (1970) and others that federally regulated interstate airfares exceeded those of comparable unregulated intrastate services. The issue, however, became largely one of whether turning over the industry over to market forces would create more problems of market failures than were manifest under the existing regulatory regime. There may be alternative forms of regulation worth trying. Four broad thrusts in thinking broke the deadlock and have subsequently remained important in the way transportation economists think about and assess regulatory interventions. ${ }^{10}$

Market Structures. The existence of "economies of scale" (not the economies of density, scope, and networks isolated later) led to the fear that monopoly power would result from deregulation. The development of an idea initially developed in the $19^{\text {th }}$ century by the British economist Chadwick and tinkered with in the 1950s by the likes of Bain in his limit pricing analysis, led to the emergence of contestability theory. The power of potential market entry in the absence of sunk costs, it was argued would temper the pricing actions of incumbent suppliers. William Baumol (1982) pushed the idea in his presidential address to the American Economic Association and, with co-authors, developed a more comprehensive analytical framework. The idea, however, in its embryonic form was around in the mid-1970s at a time when the future of transportation regulation in the United States was under review. It was also a powerful force in the debates in the early 1980s concerning the deregulation of the bus industry as well as the airlines market and influenced thinking elsewhere. In Europe the idea was featured in the arguments for the Single European Market.

The theory, although not accepted by all (Kahn 1988), was seen as particularly applicable to air transportation where, at very little cost, a carrier could move capacity to a competitor's route if 
the latter began to make excess profits and could, at equally trivial cost, move capacity out again if the action proved unprofitable. Any monopoly power would be transient in the hit-and-run world. Following deregulation of U.S. domestic airlines, the experiences suggested that potential competition was exercising a positive influence. For example statements included, "[I]t is highly plausible that air travel provides real examples of contestable markets" (Baumol et al. 1982, p. 7), and "in some ways the airline industry presents a particularly close approximation to contestability" (Bailey and Baumol 1984, p.128). Also "In short, in terms of the airlines' case we can infer that market forces through the pressures of competition, both actual and potential, have done a commendable if imperfect job in protecting consumer interests” (Baumol and Willig 1986). ${ }^{11}$

By the mid-1980s, this view had damped somewhat as airlines began to consolidate, hub dominated networks materialized, and incumbent airlines had become creative in developing and protecting their markets through control over computer reservations systems, frequent flyer programs, and alliances. The conclusion, even by advocates was, "We now believe that transportation by trucks, barges and even buses may be more contestable than passenger air transportation" (Baumol and Willig 1986, p. 24). And those who were never enthused about the airline industry being inherently contestable were content to reflect that "airline competition can be explained well by established concepts of market structure and entry” (Shepherd 1984, p. 585). A series of empirical studies has provided more concrete support for the relatively weak effects of potential market entry on airlines fares (Moore 1986 and Morrison and Winston 1987).

Remaining with aviation as our example, the more immediate difficulty is that, while users have benefited from regulatory reform (Morrison and Winston 1986), many airline markets have now become unprofitable for the suppliers and bankruptcies (including Chapter 11 bankruptcy in the United States that retains the integrity of a company but allows restructuring of its debts) have become common. There has always been widespread entry and exit from the market as regulations have been removed, and particularly so in the low-cost carrier bracket where few airlines survive for a length of time. This conflicts with the "post-contestability" notion widespread in the late 1980s and 1990s of inherent monopoly power in the industry. ${ }^{12}$

The difficulty is that with a scheduled service, airlines and other forms of transportation have a commitment entailing a sunk cost (having a plane, crew, fuel, etc. available at a given place and at a given time). If there is competition then this leads to fares being pushed down to short-run marginal cost with full costs going unrecovered. Although Edgeworth highlighted this general problem in the latter part of the $19^{\text {th }}$ century, perhaps because of the obtuse nature of his mathematics and a lack of familiarity with ancient Greek on the part of modern economists, it has largely been forgotten. Coase (1960) does deal with the problem and points to the need for ad hoc market powers in these cases if costs are to be recovered. In fact, airlines did have these powers when they controlled CRS systems and hub airports, initiated frequent flyer programs, and developed alliances. The advent of on-line booking has taken away their monopoly over information and reduced the potency of yield management, and high load factors have de-valued frequent flyer rewards. This type of market problem is not only found in the air transport sector but also extends to modes such as liner shipping (Pirrong 1992 and Sjöstrom 1989) where the same challenges remain of seeking to exploit the benefits of competition when confronted by sunk costs.

The Institutions and Tools of Regulation. While all did not accept the notion of contestability, there were other forces suggesting that markets, imperfect as they may be, are preferable to regulation. In particular, the traditional idea that regulators serve the public interest came into question. The idea of regulation serving the public interest is premised upon there being no "principal-agent problem.” As the Harvard economist Harvey Leibenstein demonstrated in the 1960s, and others such as Kenneth Galbraith articulated in a more popular manner, employees tend to serve their own interests rather than that of the public. Stigler (1971) had began a debate about the role of economic regulation as a sort of "commodity" in its own right, and argued that the creation of regulatory bodies was designed to transfer market protection to some incumbent group in return for its political votes. Peltzman 
(1976) developed this idea of capture further by arguing that regulators seek to serve their own purposes by de facto, acting to enhance their power through larger bureaucracies and more complex regulatory structure.

It subsequently became appreciated that even if the regulator is serving the desires of its principal, capture may still be present in the system and stymie the policy objectives. Posner (1975) and others have pointed to the significant amount of information needed to impose traditional rateof-return and market entry regulations that characterized the pre-1980s. In terms of rate setting, it was the transportation supplier that was largely responsible for reporting its costs upon which rates were based. The incentive to minimize these costs was, thus, not very strong and 'gold-plating' and $\mathrm{X}$-inefficiency resulted.

Transportation economics adopted not only these more or less comparative static approaches to the importance of institutions in shaping regulation, but has also offered some case study analysis of the dynamics that can bring about change in regulations. In particular, Keeler (1984) used elements of Starkey's theories of coalitions to explain changing attitudes towards the regulation of the United States domestic airline industry and Button (1989) made some efforts, using similar implicit gaming approaches, to look at the drivers behind the regulatory reforms to the United Kingdom bus industry.

Where there is still a perceived need to regulate a transportation undertaking, new forms of institutional structure have emerged along with innovative instruments of regulation. In particular, the traditional rate-of-return that sought to minimize allocative inefficiency and allow exploitation of scale economies has given way in many cases to price-capping with the emphasis on maximizing $\mathrm{X}$-efficiency and dynamic efficiency. Price-capping in its simple form involves setting a maximum average annual price rise across a set of services that does not exceed (RPI-X)\%; where $\mathrm{X}$ is a number determined by the regulator and RPI (the retail price index) is an index of general prices (Littlechild 1983). Although slow to be applied in the United States and where adopted it has been in rather complex forms, price-capping has been pursued in the United Kingdom and elsewhere; e.g., to regulate the BAA that owns the main U.K. airports and NATS, that owns the air navigation system.

There is ample evidence that most price capping regimes have proved powerful in squeezing Xinefficiency, both static and dynamic, from transportation undertakings, as prices have been driven down to minimum cost as the complexity of the regulatory regimes have grown. In many cases, it is now difficult to distinguish between the traditional rate-of-return approach and price capping. As a result, there is scope for considerably more thought being devoted to this topic, perhaps in terms of benchmarking or the like being used by Eurocontrol to compare the performance of air navigation systems, or the role of not-for-profit institutions.

Providing Infrastructure and Subsidies. That the public sector should be responsible for largescale transportation infrastructure was one of the few intrusions into the market that Adam Smith sanctioned. His argument was largely in terms of the inability of the private sector to raise sufficient funds for major projects; a situation that has ironically been turned on its head more recently as international financial markets have moved to fill voids left as governments have been reluctant to increase taxes for such investments. Neo-classical economic thinking was slightly different. While tending to place an emphasis on competition in the market, it was felt that inefficiencies arise when there are fixed costs and monopoly tendencies. A traditional way of handling this in the transportation context has been through state or local authority ownership, e.g. of the roads, air traffic control, airports, seaports, and metro systems in the United States but extending to railways in Europe. This has seldom proved effective, mainly due to the principal-agent problem alluded to earlier, but also because the political decision-makers found it difficult to define a consistent strategy for their agents to pursue. There have been similar problems when facilities have been left in private hands but awarded subsidies to cover full costs; how to allocate and fund the subsidies is the issue. 
The crucial change here has been in the recognition that competition for the market may substitute for that within a market. Allocative efficiency can be enjoyed with adequate investment. These ideas, often traced to Demsetz (1968) have led to a variety of institutional changes and refinements. They also tie in with the advances that have been made in auction theory; auctions can provide a basis upon which competition for markets can be generated (e.g. Rassenti et al. 1982). The United Kingdom effectively adopted auctions for allocating subsidies to its social bus services following deregulation and privatization (White and Tough 1995), and has also used them in franchising arrangements for its air navigation system, railways, and road construction.

Despite their quite successful adoption for allocating subsidy contracts, the move towards competition for the market as far as transportation infrastructure is concerned has moved relatively slowly. Developing practical auctions for many types of transportation infrastructure franchises has not been easy. While, for example, airlines are deregulated in many countries, the associated infrastructure generally remains as a regulated monopoly. The challenge has been to devise appropriate auctions for divesting the infrastructure. Problems range from the nature of the auction, through the period of franchise, to the definition and boundaries of the facilities that are put up for bidding (Button 2006). While a variety of techniques exist, turning them into practical schemes that provide an acceptable level of competition for the market has proved difficult.

Measuring Costs and Efficiency. The advent of cheap and easy computing combined with the creation of useful software has allowed economists to move away from the one-run-a-day estimations of simple regression models still common in the late 1970s. This new computational power has permitted far more sophisticated models to be estimated using less crude econometric and programming techniques. While these did not have a strong impact on the early moves towards regulatory reforms, they did influence later developments, especially in Europe, and have enabled subsequent assessment of the changes and some fine-tuning of systems. Two areas of particular note are the development of more flexible cost functions that allow for the particular characteristics of network industries, and both econometric and programming techniques that allow study of the degree of X-inefficiency that may exist under different market and regulatory structures.

Cost analysis had long been restricted to the use of fairly simple functional forms (e.g. assuming an underlying Leontief, Cobb-Douglas, or CES technology). More flexible forms, and most notably the trans-log formulation, combined with new estimation procedures to enhance the reliability of parameters (notably the seemingly unrelated least squares methods) circumvented the need to prespecify the exact form of the cost function prior to estimation (Braeutigam 1999 and Pels and Rietveld 2001). These models often generated entirely different conclusions than the more restrictive forms. As a personal example, work I did with Kevin O’Donnell (1985) indicated economies of scale in the United Kingdom bus industry whereas prior Cobb-Douglas based analysis indicated none. Unfortunately, the U.K. government's conservative tendency led to privatization of the sector on the assumption of no-scale effects as large fleets were split up and sold as small businesses. The subsequent consolidation of much of the industry into large fleets suggests that the basis of this policy was incorrect.

Also of importance is the ability of modern econometric techniques to isolate separate elements of the cost function, and in particular economies of scale, scope, and density. In some cases, the techniques have simply provided a more powerful tool for considering traditional scale effects (Tolifari et al. 1986) but in others it has disentangled the elements of scale economies. The works of Caves, Trethaway, and associates are particularly noteworthy in this context. These distinctions, not fully understood at the time of the early deregulations in the United States, provide a basis for understanding and measuring the size and form of transportation networks. Prior to this work the key network characteristics of transportation supply were largely neglected (Economides 1996) and the type of regulatory environment in place tended to be thought of in a generic sense and akin to those needed in steel, coal, banking, and other non-network industries. 
The main rationale for regulatory reforms was to reduce costs by reigning in X-inefficiency. Measuring this, and the impacts of regulatory change, has been possible both because of the development of econometric methods, such as stochastic frontier analysis, and programming techniques, such as data envelopment analysis. ${ }^{13}$ Studies deploying these methods have shown both wide-ranging variations in initial efficiency across different types of regulatory structures and significant changes in efficiency as regimes have been modified.

There is, however, something of a shadow emerging over this type of applied economics. The extent to which further insights into costs may be gleaned is more likely to depend upon data availability than on any major changes in the techniques deployed. Deregulation and privatization have, by necessity, led to more commercial confidentiality and a drying up of many of the traditional data sources that accompanied regulation. Many studies now mine deeper into older data sets and splice these with what additional information is available. There has also been a growth in metaanalysis that seeks to combine and tease out more information from prior studies (Button et al. 1999). All of this has shown a high degree of inventiveness on the part of researchers but the effectiveness of this type of work inevitably diminishes over time and is often a weak substitute for the use of up-to-date primary data.

\section{The Economics of Congestion}

Traffic congestion in urban areas, but also on other parts of transportation networks, has been a traditional challenge for policy makers. The experiences of area pricing in Singapore in the mid1970s, seen at the time as politically unacceptable elsewhere, have now been replicated in London and Stockholm and in the variable tolling of elements of freeways in California. The contributions of economics to these decisions seems important but not overwhelming - the mayor of London supported the idea after reading an obscure, non-technical paper on the subject by Milton Friedman. Equally, the plethora of technical papers on how the optimal tolls should be estimated seem to have given way to blunt pragmatism; $£ 5$ (about \$9-\$10 U.S.) a day in London when the scheme was initiated.

Nevertheless, because abstraction runs ahead of application, there have been advances in our understanding of the implications of congestion charging that may, in years to come and as advances continue in such things as information technology improve, have real relevance. Certainly, at the purely intellectual level there have been significant changes in the detail of our understanding and the elegance of much of the modeling that has been undertaken. ${ }^{14}$ Our discussion centers on road congestion and road pricing but thinking of congestion pricing for seaports, railways, and airports has also developed. ${ }^{15}$

Refining Congestion Pricing Theory. The idea of using electronic technology to collect a real time, variable congestion charge was initially advanced in 1959 by William Vickrey in evidence to a United States congressional committee. Vickrey's (1969) subsequent development of a bottleneck model, where congestion is assumed to arise when vehicles queue behind a bottleneck, has been the basis of much of the later work by Arnott, De Palma, Lindsey, Verhoef and others seeking to define the appropriate parameters for variability. All commuters wish to arrive at work at a certain time but there is a bottleneck with finite capacity that will not allow all of them to arrive at their preferred time. There are expenses associated with early and late arrival that, together with the toll, are added to the cost of the trip, that commuters try minimizing by choosing their departure time. Queuing time evolves during the rush hour and this imposes a time pattern of departures. The evolution of congestion over the rush hour is thus endogenously determined.

In its ideal form, road congestion pricing is designed to produce a Pareto optimal use of a facility but this is dependent upon the standard assumptions that surround first-best partial equilibrium analysis, and especially that all other prices are equal to marginal costs. Moving into the realm of "second-best," where the assumptions of the Pareto world are relaxed, is less tidy and inevitably 
the efficient price becomes situation specific. This more realistic situation has proved to be a fertile ground for economists over past decades.

One particular issue that is often addressed is the pricing of substitutes to road transport, and notably public transport. A road user in the absence of road pricing will only consider the marginal private cost of a trip that is lower than the full marginal social cost of the road space taken up. A subsidy to public transport, accurately reflecting the cross-elasticity of demand between the modes, could theoretically be used to attract sufficient motorists from the roads to modify congestion. Other current topics within second-best pricing have been the pricing of only part of a road network, or pricing subject to constraints. When some routes are priced and some are not, road users are left with a choice between a facility where access is not priced but the service quality is poor and one where there is an access price but congestion is optimized. The road price introduced on such routes must reflect the opportunity cost of not using the unpriced roads as well as the first best toll on the priced road. Ignoring the cross-effects will lead to sub-optimally high use of the unpriced facility.

Second-best considerations may also become important in the context of complements to, as well as substitutes for, a priced facility. Parking and gasoline taxes are the most explored complimentary goods although even here the literature is remarkably thin. Indeed because of the complementary nature of road use and parking, parking charges have in some cases been treated as an alternative to a road price (Verhoef et al. 1995). ${ }^{16}$ Although parking charges often involve low transactions costs, the circumstances where they can act as complete substitutes for road pricing are still very stylized in models. In a first-best world there would be optimal parking fees reflecting the opportunity cost of taking up land to park a vehicle as well as the congestion costs associated with cruising around seeking a parking spot. In practice, parking is often provided free or perverse charging regimes are employed. Such regimes are frequently structured to limit certain categories of users such as long stay users irrespective of willingness to pay. Parking fees should ideally be structured to reflect the traffic congestion caused by drivers cruising around looking for a parking place. Parking costs can also affect traffic demand by influencing the lengths of trips made over a network. Low parking fees, being a fixed cost of a trip, are spread more over a longer trip than a shorter one. This may affect congestion in suburban areas.

There is another side to the second-best debate where theoretical advances have been made that should be touched upon. There has been a mounting interest in how other road taxes, public transport fares and road investment decisions can be made in the absence of optimal road pricing. In this context, Arnott and Yan (2000) have looked at pricing across multi-modal systems; Wheaton (1978) developed ideas of second-best road investment strategies; and Chia et al. (2001) examined the appropriate fuel taxation policy to pursue if appropriate congestion charges are absent.

Much of the early work on congestion pricing treated all road users as being identical. Variations in their income and, linked to this, the valuations that they place on travel time savings, the size of vehicles driven, and the roads they take, are now appreciated as being important considerations for both efficiency and equity reasons. At the very least, they raise questions about whether the congestion charge should reflect these features. If the concern is purely with efficiency and standard first-best conditions hold, then there is no need to consider these variations with time varying congestion pricing. This is because all that matters are the congestion costs imposed (Arnott and Kraus 1998).

Where there are alternative routes in the network (including different lanes on a road), then where users have different utility functions optimality is attained by offering various congestion charge/congestion level combinations. This, as Pigou indicated in the 1920s, maximizes welfare by allowing those with a high travel time value to buy their way onto the faster routes, leaving those with a lower value on the cheaper, more congested ones. The situation can also be compared with having users with different trip-time preferences using a single route. Arnott et al. (1992) show that where there are temporally inflexible congestion charges a different charge on each of two roads is more efficient than a single uniform charge for both. 
Other situations that have attracted attention include those when drivers have different preferences for speed that are unrelated to income. Here the models have often tended to exclude the possibility of overtaking, making them particularly relevant to bridge and tunnel cases. The results suggest that the congestion charge needs to be higher for slow vehicles to reflect their impact in slowing higher speed vehicles. This would require differential approaches to congestion pricing depending on drivers' speed preferences. In practical terms this may be done by having different pricing regimes for cars and trucks.

Even if public transport is not an issue, the network is simple, and road users are homogeneous, the standard model of congestion pricing excludes any consideration of implementation and operation costs like for the costs of collecting the fees and policing the system. These may be significant and may become entwined with other issues such as how much information the road user has on the "product" that is being purchased (De Palma and Lindsey 1998). This is still a problem that is largely unresolved.

Capacity Expansions. A market price serves not only to allocate current facilities optimally but it also provides signals to where capacity should be expanded and the revenues from the price provide resources for that expansion. In a perfect market situation, effectively Knight's position in the 1920s, there is no requirement for separate consideration of capacity expansion - the net revenue flows give the necessary guidance. Given the reality of public ownership of most roads and the possibility of internalizing the congestion externality with a corrective congestion charge, there have been a number of studies looking at the link between the optimal congestion charge and road investment strategies.

An important result that provides an additional incentive for the road agency to internalize the congestion externality is that the optimal congestion covers the fixed operating cost of a road provided there are constant returns to scale in road construction and maintenance and capacity can be increased in continuous increments. In this sense, as Newbery (1989) and others have demonstrated, a road charge equal to the sum of the optimal congestion charge and the road damage charge covers the fixed operating cost as defined above and the variable maintenance cost. This is the case provided there are constant returns to scale in construction, maintenance and use of road capacity.

Under constant returns and optimal pricing, whenever there is economic profit, the capacity of the road should be expanded, and when there is economic loss, the road has been overbuilt and should be abandoned or closed. The optimal pricing and investment decision for roads can thus be dealt with in a single model (Keeler and Small 1977). When there are diseconomies of scale then at the optimal capacity and with an optimal congestion charge, economic rent will be earned. This reflects a scarcity rent on a fixed factor of production, in this case, the land. Equally, if there are economies of scale, and in some instances when there are large indivisibilities in investments, the optimal congestion charge will not generate sufficient revenue to cover the fixed operating cost. Subsidies will be required and techniques such as cost-benefit analysis come into play in determining their level.

Much, therefore, depends on the view taken about the nature of returns to scale and indivisibilities in road investment and we do now know a little a more about the economics of this. Kraus (1981) argues that the existence of lanes implicitly means that there are indivisibilities in supply. In contrast, Starkie (1982), following the legacy of Keeler and Small, looks at a road network as a whole and argues that within that context, actions such as resurfacing, changes in lane width, etc, can be varied incrementally. Hau (1998) finds that increasing, decreasing and constant returns to scale all exist in road transport and each case should be assessed individually.

The Value of Travel Time Savings. While road pricing results in an overall welfare loss to road users, some of those who continue to use the roads do benefit from faster trips. Others, while paying a higher monetary price for their road trips, have this cost at least partly offset by time savings. Time is a significant cost component of any trip and its value is therefore of fundamental importance. The 
literature is extensive and goes back to the 1960s (e.g. Beesley 1965 and Moses and Williamson 1963). Indeed different values of travel time and travel time savings can lead to different answers on the viability of a transport project.

The recent and extensive literature on the subject now offers ample evidence that the value of time varies among population subgroups according to income, gender and age, and also with trip purpose, mode used, length of the trip, prevailing conditions of congestion and sometimes weather. The value given to the travel time variation depends on the sign (loss or saving) and the magnitude, and its ratio to total travel time. As a consequence of this, any congestion pricing proposal needs to be evaluated on an individual basis, paying particular attention to the socioeconomic characteristics and trip patterns of the road users to be affected. The value of the travel time savings will play a substantial role in the net benefits to be derived from any transport project, including congestion pricing schemes.

The Political Economy of Road Pricing. Political economy has begun to play an increasing role in the way that economists think about congestion charging. In a purely competitive private market, large amounts of revenue generated by a road congestion regime would signal that road use is highly valued and the net revenues should go towards enhancement of the network. This approach also brings down the future cost to motorists of using it. In a second-best situation, characterized by a variety of market and government failures across the economy, this is not automatically the best way to spend the revenues. Those concerned with distributional effects essentially accept that congestion pricing may result in a potential Pareto improvement in as much as theoretically those who gain could be "taxed" to yield compensation to those who lose out and still enjoy a net benefit.

The problem however is that congestion pricing projects without some official policy tend to lack any actual compensation mechanism. As Small and Gómez-Ibáñez (1998, p.239) observed, "Winning political approval for any form of congestion pricing project is difficult in a democracy, even with careful planning." There may be a number of reasons for this but the political economy of road pricing has largely centered on the distribution implications of the policy. This is hardly surprising because it is the road user who immediately loses as a result of charging for congestion. While economists tend to focus mainly on the efficiency implications of transport policies, politicians and administrators put more emphasis on the various effects on different groups in society.

As a first step in introducing incidence into the analysis it is necessary to know exactly who gains and who loses, and in what ways. The distributional impacts will typically depend on the nature of the congestion pricing regime. While there are important theoretical contributions in this field, the studies have been mainly empirical in their approach. What emerges from this mainly empirical literature on the distributional impacts of congestion pricing is a lack of consensus. Layard (1977) argues that the policy is regressive. In an early paper, Foster (1975) argues that it is progressive. Giuliano (1992) takes a somewhat different position, namely that even if congestion pricing is regressive, the fact is used to disguise other objections to the policy rather than necessarily being important in itself. Santos and Rojey (2003) conclude that the distributional impacts depend on the design of the scheme and the geo-economic characteristics of the town in question (where do people live, where do they work and how do they get to work).

This body of positive economic analysis is inevitably linked to the often more normative matter of the various ways in which the revenues from a congestion charge can be spent. Newbery (1990) suggests that revenues from congestion pricing in the United Kingdom could to be returned to motorists in the form of lower fuel duties. Motorists as a group would then be made better off as they would pay the same total road user charges but would experience less congestion. Small (1992) and others propose that revenues should be allocated in thirds, one third to the reduction of taxes in general, or fuel taxes, or vehicle license fees or to the increase in social expenditure, one third to investment in public transit, and one third to investment in new roads or reimbursement to trip makers. Although arbitrary, this allocation in thirds would aim at compensating losers and promoting improvements in the transport sector. 


\section{Traffic Modeling}

One among many contributions to the centennial edition of the Economic Journal was a paper by Milton Friedman (1991), an economist famed for introducing Ken Livingston, the Mayor of London, to the idea of congestion pricing. Friedman points to the considerable increase in the use of mathematics and formal modeling in economics; a reflection of the almost complete capture of the subject by the deductive school. This is understandable in many areas of transportation economics where the economic input is ultimately into engineering decision-making (such as pavement depth, bridge structures, and junction design) and hard numbers become important. It is also important when it comes to making financial decisions at the micro level regarding such things as levels of subsidy and assessment of regulatory pricing regimes. There have been marked advances in the techniques available to fulfill the function.

The changes in the way economists have developed their formal models and calibration procedures have been stimulated by a variety of sources including new demands on the part of decision-makers regarding the nature of the information required, fresh ideas that have emerged more generically in economic theory and econometrics, and by the enhanced ability of modern computers to handle more complex estimation procedures and to do so quickly and cheaply. Some indication of the changes that have occurred since the 1970s can be seen in traffic demand modeling and efficiency measurement techniques.

\section{Travel Demand Modeling}

Traditional Travel Demand Modeling. The traditional way of forecasting traffic developed in the 1960s as part of the mega-transportation land-use/transportation studies carried out in Chicago, the Puget Sound and elsewhere involves a four-stage recursive, sequential framework operationalized through a series of mathematical models (McNally 2000). The exact details can vary but a reasonable description is that trip generation and attraction for each zone of an area are forecast based on predicted socioeconomic trends of each zone. This traffic is then allocated across all possible origin and destination pairs according to their relative attractiveness and the difficulties in moving between them. The traffic is then split according to the likely modes of transportation that will be favored according to the relative costs of the alternatives and then the traffic is assigned to individual routes.

The modeling structure was developed at a time when computing power was limited, requiring a division of tasks for tractability, and when what may be seen as "blue-print" planning was in favor. The plans were long-term and designed to provide a picture of how infrastructure investments should be implemented over this time frame. It was pointed out at the time by economists and others that there were limitations to the approach and the past three decades have seen considerable modifications.

At a practical level, the series of calculations required to calibrate this set of equations places tremendous strains on the data base available and, in most studies, large and expensive surveys are needed to gather the necessary information. Reviewing and updating the forecasts was largely impractical. But from an intellectual perspective there are also problems with the sequence. While each model could be assessed for its ability to replicate the current situation, assessment of the overall fit of the recursive sequence was not possible. From a strict economic point of view several of the sub-models had serious intellectual defects; one example suffices to show the nature of the problem. The trip generation model used to forecast the overall traffic demands in a city essentially assumed a vertical demand curve for aggregate travel that shifted as socioeconomic variables such as income or family size changed. There was no price variable in most models although changes in the size and use of the transportation network had been understood to affect aggregate demand since the work of French Engineering School of Economists in the 1840s and 1850s (Ekelund and Hébert 1999). More recently, traffic engineers have suddenly discovered the notion of "latent demand," 
de facto a negatively sloped aggregate travel demand curve. They have sought to embody this in models as some form of accessibility factor that reflects changes in the overall costs of travel in the study area.

Of equal importance to the rather weak intellectual foundation of the model is the fact that transportation planning has taken on new forms. In particular, while transportation strategies still need to be defined they tend to be much more fluid and less aimed at drawing up a blue print for the future. There is also far more emphasis on managing the transportation system than with providing adequate infrastructure to meet an unrestricted demand. Added to this, the large-scale deregulation and privatization of transportation in many countries has led to the development of models that focus more on the behavior of transportation industries and less on the detailed control of these directly by public authorities.

Disaggregate Models. The substantial data input required to calibrate satisfactorily the submodels and the difficulty of transferring models once estimated from one data area to another, combined with dissatisfaction with the basically mechanistic and physical nature of the sequential approach, resulted in an alternative mathematical approach being developed by economists (e.g. Quandt 1976). The disaggregate method of travel demand forecasting that emerged emphasizes the economic-psychological influences on travel behavior at the individual household level. The idea is that households are utility-maximizers who, mainly for mathematical convenience, are considered to make travel decisions in isolation from other activities. The emphasis is on short-run decisions rather than long-run mobility decisions. Small, stratified samples of households (500 or so) provide the data input into the models which tend to be probabilistic, rather than deterministic, in nature. That is, they forecast the probability of particular household travel patterns rather than the average number and type of trips to be undertaken. For planning or assessment, the forecasts produced from models are aggregated up to the level of the geographical zone - it is the inter-zonal level, for example, that determines the level of public transport demand. While there are claims that the approach can be used in comprehensive transport planning, its main role to date has been in policy assessment.

Broadly, disaggregate models are characterized by two main features (Ben-Akiva and Lerman 1985). First, they explicitly recognize that travel decisions emerge out of individuals' optimizing behavior and, if it is pointed out that the final goods consumed as a result of travel are normal, then at a very minimum the demand for travel ought to be related positively to disposable incomes and negatively to the prices of transport services. Secondly, most have their origins in the "attributal theory of demand" associated with Lancaster (1966). This approach to human behavior assumes that people desire to maximize a utility function that has commodity attributes rather than the quantities of the actual goods consumed. As an example, if one is considering air transport between the United Kingdom and United States, then the alternative commodities would be the different fare-packages offered by the airlines, and the attributes of each would be characteristics such as money costs, speed, period of advance booking, timing, type of aircraft, on-plane service, stop-over regulations, and required length of stay at destination.

Direct attempts were made to apply Lancaster's theory at the aggregate level. At the interurban level, Quandt and Baumol (1966) attempted early on to construct an abstract mode model for air, bus and car journeys between 16 city pairs in California using cost and time (both absolute and relative) as the determining attributes. The results were inferior to those obtained from more conventional trip-distribution models. While some of the calibration problems that were associated with the early aggregate abstract mode models have been resolved since this work, it has been the introduction of the random utility model (RUM), that have marked the greatest advances. This offers both a basis for calibrating models and an intellectually consistent framework that fits with modern utility theory.

The major advance in this context was the realization that each individual has a different utility function, partly because of quantifiable differences in their personal characteristics, but also partly 
because of random factors. While the heterogeneous nature of the population poses serious problems, the work of Domenich and McFadden (1976) in modeling the random factors, and especially their theoretical work on justifying the use of "multi-nomial logit models," forms the basis of much modern disaggregate analysis. The forms of disaggregate models that have been developed along these lines, and the range of applications to which they have been applied, are many. The power of the RUM model was illustrated in the early 1970s when McFadden and co-workers applied the approach to a sample of 631 individuals in the San Francisco Bay Area to forecast the use of the new BART system. Even with what would now be seen as a primitive model, their forecast of a $6.3 \%$ mode share compared favorably with the $6.2 \%$ outcome and the $15 \%$ or so official forecast made using a conventional gravity model. There subsequently have been significant refinements to McFadden's initial framework. ${ }^{17}$ There is also considerable evidence that the use of this modeling framework, even in the context of more narrow objectives such as transit demand elasticity estimation, produces more reliable estimates (Oum et al. 1992).

Experimental Economics and Stated Preferences. Since the ability to conduct strict experiments in economics is extremely limited, quasi-experimental procedures have been used whereby econometric techniques have been employed to allow for background "noise." Traditional transportation forecasting models relied upon revealed preference data a là Samuelson. That is, actions were observed and measurements taken to calibrate models. In contrast, experimental economics, as developed by the Nobel Prize winner Vernon Smith, among others, make use of synthetic data that is gathered through a stated preference methodology. Rather than observe actions, various forms of sophisticated questioning or simulation techniques are used to gain values within a set of stipulated circumstances. Such techniques are now widely used in transportation demand modeling (Louviere and Street 2001) and for evaluation, especially of environmental externalities and public goods, where a widely used sub-set of stated preference techniques is "contingent valuation" (Carson 2000). ${ }^{18}$

Experimental techniques are clearly a powerful tool when applied correctly but have limitations. Judging by the almost total lack of fertilization of experiences from the mainstream economics literature in the field relating to applications to transportation matters, these techniques are still not fully mature. Setting aside a series of econometric issues (Bates 1988 and Fowkes and Wardman 1988) inherent in using such data, a major problem is the setting up of the scenario within which subjects make choices. Early analysis tended to involve questionnaires, and these are still widely deployed in transportation applications, but much of the experimental work has moved onto computerized simulations. These simulations allow individuals to interact in the "game" being played - important, for example, in making route and choice decisions where congestion may occur. Setting up these experiments takes time and care in specifying the background scenario against which "questions" are posed so that each participant has similar concepts in their minds when responding. This requires expertise more commonly found among psychologists than economists, and indeed in other areas of economics where it is applied, those involved frequently have joint qualifications.

There are also issues of transferability. Because each stated preference exercise is based upon posing questions in a hypothetical, semi-controlled environment, against a carefully specified background scenario, it is difficult to generalize across studies that use different scenarios. The normal condition of value or functional transfer that allow for wider adoption of such things as elasticities and valuations of externalities are violated and their adoption in any form of meta-analysis must be in doubt because of the problems of defining moderator variables (Bal et al. 2002).

\section{WHERE SHOULD THE FOCUS BE NOW?}

We have seen that transportation economics has changed considerably in the past 30 years but many challenges and interesting topics for analysis remain. However, prioritizing these and deciding how to move forward is not easy. Just as in the mid-1970s it was impossible to foresee what would occur 
three decades hence, so forward looking now is difficult. A few general observations, however, are offered as to the ways that economists can continue to contribute insights to and newly arising ones are offered, together with a couple of specific topics that seem in need of a concerted research effort.

At the outset it should be recognized that there is a general problem in economics that academic kudos and career advancement now almost automatically go hand-in-hand with abstraction. It is much less impressive, and hardly a useful way to develop an academic career in economics, to work on how to implement a practical road congestion charging regime than to work out the optimal charge to passage of vehicles over a three way junction with mixed traffic on a weekday. But oddly enough, the latter is often easier because it largely avoids the complexity of human behavior. It is not difficult to see how this divergent position has come about, and an article written by Michael Beesley (1989, p. 17) sums up the root causes rather well when he points to the need for the academic economist to gain promotion to show competence "which can potentially have a wider application than in transport. Transport as a specialism does not in itself yield much career advancement.” He goes on to argue that detailed study of the institutions and nuances of a single market to assist policy makers in future decisions does not result in career advancement. He is probably largely right in this since the focus in economic research is often retrospective in the sense of looking at existing problems rather than looking forward but perhaps less so than Beesley believed; at least it is hoped so. ${ }^{19}$

There is also another dimension in which transportation economics could become more "useful" and that is to do with its interface with logistics. ${ }^{20}$ Some time ago, Harvey Leibenstein (1979, p. 477) complained that microeconomics treated business as something of a black box and had really done little to try to understand the internal workings of firms; "The question of how individuals in multiperson firms influence firm decisions seems like such a natural question to ask that it is amazing that it is not part of the formal agenda of economists as a profession.” In a way the study of supply chain logistics has begun to fill this void by offering analysis of how decisions are made in firms (the "positive" dimension) and how they should be made (the "normative"). The importance of the supply chain has risen to the top of the agenda among management scientists and the role of transportation within the larger value chain has been recognized (Porter 1985). This does not quite meet all of what Leibenstein would ask for - his main focus was on motivational factors - but it does provide movement in that direction.

The challenge is perhaps to get more transportation economists interested is supply chain issues. Logistics has developed as the interface of transportation and telecommunications and has allowed for greater control over the supply-line and more information about demands that will be placed on elements of it (Button and Stough 2006). These developments have facilitated such things as lean production and just-in-time management. Economists were never really ignorant of the importance of good internal management; indeed eminent economists such as Baumol produced early work on inventory control (Baumol and Vinod 1970) and economic programming more generally. Nevertheless, there still exists a void between many of those involved in logistics in management schools and academic transportation economists.

One of the difficulties is that logisticians often rely more upon inductive methods than is the convention in traditional economics, despite the views of a father figure like Alfred Marshall who was himself quite inductive in some of his work. Given the importance of logistics, and the very clear role that economic considerations have for its efficient application, and the insights that managerial science can offer to transportation economics, there are tremendous synergies to be exploited here. The challenge could perhaps be seen as parallel to the ways in which lawyers, regulators and economists functioned in the past. That is, there were differences but these were outweighed by the complementarities in their approaches. The same types of link could form with those in management, although at the practical level, the private sector ethos of many business school concepts is perhaps difficult for some academic economists to grasp outside of their models. The difficulty of doing so again goes back to Beesley's point about the lack of any real motivation for those setting out on a career in economics. 
Now to one or two specific issues where economists do not seem to have been pulling their full weight.

First, there must be some concern that economists have had so little to say about transportation security. There have been papers that have essentially tried to cost various measures introduced by government but more conceptual work has been very limited and the field has largely been left to management scientists and the suddenly abundant "security experts." ${ }^{21}$ Given the resources being devoted to the area, and those that are likely to continue to flow into the foreseeable future, this would seem to be a missed opportunity. The subjective nature of the objective function makes it an ideal field for experimental economics, and the complexity of the institutional considerations, both formal and otherwise, would seem to offer scope to those that specialize in that area.

A second area concerns the more aggregate question of just how important transportation is to an economy. Microeconomics offers techniques for assessment at the project and individual policy level but the implications of policies influencing the overall resources devoted to transportation is a critical one for many governments and for international agencies such the World Bank. At a slightly lower level of aggregation we also really know very little about the overall economic role of individual modes. Much of the debate on these topics tends to be at the level of political lobbying and often based on inappropriate aggregate methodologies. National Income Accounts, often used as a basis for trying to quantify transportation's role are manifestly unsuitable because of their intrinsic Keynesian basis. Kuznets, Stone and others who constructed their foundation were essentially looking for a lead indicator for aggregate unemployment. Equally, Leontief's inputoutput analysis, although not an aggregate framework, was devised to look at system shocks or for potential factor shortages when there were relatively small changes in a particular sector; hence its lack of any explicit supply constraint and the linear production functions assumed by Leontief.

Regional and spatial economists generally incorporate transportation in their models but even more micro studies at the regional, local level or project level focus on the immediate impacts on a particular geographical unit and generally ignore the degree to which changes reflect transfers from elsewhere rather than a genuine societal gain. A gain to one region may be at a larger cost to another. There would seem scope, however, for developing some of their analysis further to take into account the large economic impacts of transportation on economic performance.

\section{CONCLUSIONS}

Our understanding of the economics of transportation has been enhanced considerably over the past 30 years or so. All we have to do is look at the current set of textbooks to see this (Button 2007 and McCarthy 2001). On the more institutional side there is Gómez-Ibáñez et al. (1999). In particular, there has been an acceptance that economists can contribute to many of the debates that had traditionally been the preserve of civil engineers and lawyers. There is now more, and I think better, quantitative analysis of issues. Many of the changes have been the result of the adoption of theoretical and technical developments more generally, but there are also cases, for example regarding regulatory theory, demand forecasting, and congestion theory, where developments have been inspired by the particular challenges of efficient transportation provision.

Overall, I think it is safe to conclude that the contribution of economics to solving transportation problems over the past 30 years has been positive, although inevitably, with more impact on decisionmaking, it could have been greater. Significant economic challenges remain to be confronted if transportation is to fully achieve its social potential. We are still some way away from Keynes's (1931, p. 373) view that "If economists could manage to get themselves thought of as humble competent people, on a level with dentists, that would be splendid."22 The problem is perhaps that economists are seldom humble, and often have no desire to be, often are reluctant to work with those from other disciplines, and are still frequently poor at stating their case in a way that business people and policy makers can appreciate. 


\section{Endnotes}

1. Additionally, while the paper is quite heavily referenced, it is not an annotated bibliography and thus in places offers direction to other, narrower review papers rather than give a comprehensive set of references to primary sources.

2. The interest in the role that transportation infrastructure may play in stimulating economic productivity was resurrected by Aschauer's (1989) empirical analysis. Assessments of this and associated literature are to be found in Winston (1991) and Button (1989).

3. As a personal plug, this subject is pretty well covered in Transportation Research D - Transport and Environment; a journal that I edit.

4. Institutional in the older sense of the term rather than that of the New Institutional Economics of Oliver Williamson, Ronald Coase, and others.

5. Combined these volumes amount to about 1,500 pages but contain only five or so line-diagrams and no equations, although there are quite a few maps of transportation networks.

6. It gained quite rapid recognition and in a survey by Button and Pearce (1977) seeking the views of United Kingdom academics on the prestige to be gleaned from publishing in various outlets scored highly, especially since it was a "write-in” item.

7. Button (2003) contains a collection of the more recent major papers in the field. For a sort of "half-way house" on changes in transportation economics over the past few decades see Winston (1985).

8. In Europe the terms ‘liberalization' or 'regulatory reform’ are preferred.

9. In fact the first significant deregulation was of the United Kingdom trucking industry under the 1968 Transport Act and in the United States there was some earlier regulatory reforms to the freight railroad sector under the 1976 Railroad Revitalization and Regulatory Reform Act.

10. The formation of the Transportation Research Forum in the 1960s provided a place for economists, including those in government service, to explore ways for lessening the regulation of the railroad industry in particular.

11. Although the market was not perfectly contestable, the evidence still indicates that the overall effects of deregulation seem to have been largely beneficial (Morrison and Winston 1987 and Levine 1987). The same applies to most other transportation industries that were the subject of similar 'treatments.'

12. I rather egocentrically point to my own paper on the subject that foresaw the situation in the mid-1990s (Button 1996).

13. The former, as with standard econometric techniques, allows for hypothesis testing whereas the latter is essentially descriptive but both have their uses. Studies in transportation and other sectors indicate that somewhat different results may emerge using the techniques, but broadly speaking they offer consistent rankings of the efficiency of various suppliers; e.g. see Button and Weyman-Jones (1994) and Button and Costa (1999).

14. Much more detail on the modern theoretical approach to congestion and congestion pricing are to be found in Verhoef (1996) and Lindsey and Verhoef (2000, 2001), all of which contain copious references.

15. Recently, for example, airport congestion issues have been of particular interest (Bruckner 2002, Daniel 1995, Mayar and Sinai 2003). 
Transportation Economics

16. Parry and Small (2005) consider the economic roles of gasoline taxes in the United Kingdom and the United States but recognize that congestion mitigation is part of a wider set of objectives that include sumptuary revenue raising and environmental protection.

17. A account of the development of the RUM is contained in MacFadden (2001) that largely reproduces the speech given at the Nobel Prize ceremony.

18. There has been a particular interest among transport economists in using these types of technique to place a value on safety. Jones-Lee and Loomes (2003) provide a survey.

19. As a personal observation as an editor of two transportation journals, a very large number of papers pass over my desk each year. It is apparent that many of these papers are not the result of any real concern with the underlying issue being addressed but more an exercise in mental gymnastics or the author seeking a topic to which a newly discovered econometric technique may be applied.

20. Brewer et al. (2001) provides a significant number of original papers that lay out the background to current logistics practices.

21. In completing some recent work on maritime security (Brooks and Button 2006 and Thibault et al. 2006), searching the literature produced little economic analysis of the subject.

22. Keynes, by way of a diversion, always maintained his real desire in life was to run a railway company.

\section{References}

Arnott, R. and M. Kraus. "When are Anonymous Congestion Charges Consistent With Marginal Cost Pricing?” Journal of Public Economics 67, (1998): 45-64.

Arnott, R. and A. Yan. "The Two-Mode Problem: Second-Best Pricing and Capacity." Review of Urban and Regional Development Studies 12, (2000): 170-199.

Arnott, R., A. De Palma, and R. Lindsey. "Route Choice With Heterogeneous Drivers and GroupSpecific Congestion Costs." Regional Science and Urban Economics 22, (1992): 71-102.

Aschauer, D. “Is Public Expenditure Productive?” Journal of Monetary Economics 23, (1989): 177-200.

Bailey, E.E. and W.J. Baumol. "Deregulation and the Theory of Contestable Markets.” Yale Journal on Regulation 1, (1984): 111-137.

Bal, F., K.J. Button, and Nijkamp. "Ceteris Paribus, Meta-Analysis and Value Transfer." Socioeconomic Planning Sciences 36, (2002): 127-138.

Bates, J. “Econometric Issues in Stated Preference Analysis.” Journal of Transport Economics and Policy 22, (1988): 59-70.

Baumol, W.J. “Contestable Markets: An Uprising in the Theory of Industrial Structure.” American Economic Review 72, (1982): 1-15.

Baumol, W.J. and H.D. Vinod. “An Inventory Theoretical Model of Freight Transport Demand.” Management Science 16, (1970): 413-421.

Baumol, W.J. and R.D. Willig. “Contestability: Developments Since the Book.” Oxford Economics Papers 38, (1986): 9-36.

Baumol, W.J., J.C. Panzar, and J. Willig. Contestable Markets and the Theory of Industry Structure. Harcourt Brace Jovanovich, San Diego, California, 1982.

Beckmann, M., C.B. Mcguire, and C.B. Winsten. Studies in the Economics of Transportation. Yale University Press, New Haven, Connecticut, 1956. 
Beesley, M.E. “The Value of Time Spent in Traveling: Some New Evidence.” Economica 32, (1965): 174-185.

Beesley, M.E. “Transport Research and Economics.” Journal of Transport Economics and Policy 23, (1989): 17-28.

Ben-Akiva, M. and S. Lerman. Discrete Choice Analysis: Theory and Application to Travel Demand. MIT Press, Cambridge, Massachusetts, 1985.

Board Of Trade. British Air Transport in the Seventies. Cmnd 4018, London, HMSO, 1969.

Bonavia, M.R. The Economics of Transport. Cambridge University Press, Cambridge, 1936.

Braeutigam, R.R. “Learning About Transport Costs.” J.A. Gómez-Ibáñez, W. Tye, and C. Winston eds. Essays in Transportation Economics and Policy: Handbook in Honor of John R. Meyer. Washington, D.C.: Brookings Institution (1999): 57-97.

Brewer, A.M., K.J. Button, and D.A. Hensher. Handbook of Logistics and Supply-Chain Management. Pergamon, Oxford, 2001.

British Railways Board. The Reshaping Of British Railways. London, HMSO, 1963.

Brooks, M. and K.J. Button. "Market Structures and Shipping Security.” Maritime Economics and Logistics 8, (2006): 100-120.

Bruckner, J.K. “Airport Congestion When Carriers Have Market Power.” American Economic Review 92 (2002): 1357-1375.

Buchanan, J.M. “Private Ownership and Common Usage: The Road Case Re-Examined.” Southern Economic Journal 22, (1956): 305-316.

Button, K.J. “Liberalizing European Aviation: Is There an Empty Core Problem?” Journal of Transport Economics and Policy 30, (1996): 275-291.

Button, K.J. "Economic Theories of Regulation and the Regulation of the United Kingdom's Bus Industry.” Antitrust Bulletin 34, (1989): 489-515.

Button, K.J. (ed) Recent Developments In Transport Economics. Edward Elgar, Cheltenham, UK, 2003.

Button, K.J. “Auctions-What Can We Learn from Auction Theory for Slot Allocation?” A. Czerny, P. Forsyth, D. Gillen, and H.M. Niemeier eds. How To Make Slot Markets Work. Burlington, Ashgate (2006).

Button, K.J. Transport Economics (3 ${ }^{\text {rd }}$ Ed). Edward Elgar, Cheltenham, UK, 2007.

Button, K.J. and A. Costa. "Economic Efficiency Gains From Urban Public Transport Regulatory Reform: Two Case Studies of Changes in Europe.” Annals Of Regional Science 33, (1999): 425438.

Button, K.J. and K.J. O’Donnell. “An Examination of the Cost Structures Associated with Providing Urban Bus Services in Britain.” Scottish Journal of Political Economy 32, (1985): 67-81.

Button, K.J., S.M. Jongma, and J. Kerr. “Meta-Analysis Approaches and Applied Microeconomics.” International Journal of Development Planning Literature 14, (1999): 75-102.

Button, K.J. and D.W. Pearce. "What British Economists Think of Their Journals." International Journal of Social Economics 4, (1977): 151-158.

Button, K.J. and R. Stough. Telecommunications, Transportation, and Location. Edward Elgar, Cheltenham, UK, 2006.

Button, K.J. and T. Weyman-Jones. "X-Efficiency and Technical Efficiency." Public Choice 63, (1994): 80-104. 
Transportation Economics

Carson, R.T. “Contingent Valuation: A Users Guide.” Environmental Science and Technology 34, (2000): 1413-1418.

Chia, N.C., A. Tsui, and J. Whalley. Ownership and Use Tax as Congestion Correcting Instruments. NBER Working Paper 8278. Cambridge, Massachusetts, 2001.

Coase, R.H. “The Problem of Social Cost.” Journal of Law and Economics 3, (1960): 1-44.

Commission on the Third London Airport. Report. London, HMSO, 1971.

Daniel, J.L. "Congestion Pricing and Capacity of Large Hub Airports: A Bottleneck Model With Stochastic Queues.” Econometrica 63, (1995): 327-370.

Demsetz, H. “Why Regulate Utilities?” Journal of Law and Economics 11, (1968): 55-65.

DePalma, A. and R. Lindsey. "Information and Usage of Congestible Facilities Under Different Pricing Regimes.” Canadian Journal of Economics 31, (1998): 666-692.

Domenich, T. and D. McFadden. Urban Travel Demand-A Behavioral Analysis. North-Holland, Amsterdam, 1976.

Economides, N. “The Economics of Networks.” Econometrica 56, (1996): 165-185.

Ekelund, R.B. and R.F. Hébert. Secret Origins of Modern Microeconomics: Dupuit and the Engineers. Chicago University Press, Chicago, Illinois, 1999.

Foster, C.D. The Transport Problem. Croom Helm, London, 1975.

Fowkes, A.S. and M. Wardman. "Design of SP Travel Choice Experiments, with Special Reference to Taste Variations.” Journal of Transport Economics and Policy 22, (1988): 27-44.

Friedlaender, A.F. The Interstate Highway System: A Study in Public Investment. North-Holland, Amsterdam, 1965.

Friedman, M. “Old Wine in New Bottles.” Economic Journal 101, (1991): 33-40.

Giuliano, G. "An Assessment of the Political Acceptability of Congestion Pricing.” Transportation 22, (1992): 335-358.

Gómez-Ibáñez, J.A., W. Tye, and C. Winston. (eds) Essays in Transportation Economics and Policy: Handbook in Honor of John R. Meyer. Brookings Institution, Washington, D.C., 1999.

Gwilliam, K.M. Transport and Public Policy. George Allen and Unwin, London, 1964.

Gwilliam, K.M. and P.J. Mackie. Economics and Transport Policy. Allen \& Unwin, London, 1975. Harrison, A.J. The Economics of Transport Appraisal. Croom Helm, London, 1974.

Hau, T.D. "Congestion Pricing and Road Investment.” K.J. Button and E.T. Verhoef eds. Road Pricing, Traffic Congestion and the Environment. Cheltenham U.K.: Edward Elgar (1998).

Heggie, I.G. Transport Engineering Economics. McGraw-Hill, Maidenhead, 1972.

Jones, I.S. Urban Transport Appraisal. Macmillan, London, 1977.

Jones-Lee, M. and G. Loomes. "Valuation of Safety.” D.A. Hensher and K.J. Button eds. Handbook of Transport Modeling. Oxford U.K.: Pergamon (2003).

Jordon, W.A. Airline Regulation in America: Effects and Imperfections. Johns Hopkins University Press, Baltimore, Maryland, 1970.

Joy, S. The Train That Ran Away. Ian Allan, London, 1973.

Kahn, A.E. “Airline Deregulation-A Mixed Bag, But a Clear Success Nevertheless.” Transportation Law Review 16, (1988): 15-27. 
Keeler, T.E. “Theories of Regulation and the Deregulation Movement.” Public Choice 44, (1984): 103-145.

Keeler, T.E. and K.A. Small. "Optimal Peak-Load Pricing, Investment, and Service Levels on an Urban Express Way.” Journal of Political Economy 85, (1977): 1-12.

Keynes, J.M. Essays In Persuasion. Macmillan, London, 1931.

Keynes, J.M. The General Theory of Employment, Interest and Money. Macmillan, London, 1936.

Kraus, M.C. “Indivisibilities, Economies of Scale, and Optimal Subsidy Policy for Freeways.” Land Economics 57, (1981): 115-121.

Lancaster, K.J. “A New Approach to Consumer Theory.” Journal of Political Economy 74, (1966): 132-157.

Layard, R. “The Distributional Effects of Congestion Taxes.” Economica 44, (1977): 297-304.

Lebenstein, H. “A Branch of Economics is Missing: Micro-Micro Theory.” Journal of Economic Literature 17, (1979): 477-502.

Levine, M. "Is Regulation Necessary? California Air Transportation and National Regulatory Policy.” Yale Law Journal 74, (1965): 1416-1447.

Levine, M.E. "Airline Competition in Deregulated Markets: Theory, Firm Strategy, and Public Policy.” Yale Journal on Regulation 4, (1987): 393-494.

Lindsey, R. and E.T. Verhoef. “Congestion Modeling.” D.A. Hensher and K.J. Button eds. Handbook of Transport Modelling. Oxford, Pergamon (2000).

Lindsey. R. and E. Verhoef. "Traffic Congestion and Congestion Pricing." K.J. Button and D.A. Hensher eds. Handbook of Transport Systems and Traffic Control. Oxford, Pergamon (2001).

Little, I.M.D. and J. Mirlees. Project Appraisal and Planning for Developing Countries. Heinemann, London, 1974.

Littlechild, S.C. Regulation of British Telecommunications 'Profits. Department of Industry, London, 1983.

Locklin, D.P. Economics of Transportation: $7^{\text {th }}$ ed. Richard D. Irwin, Homewood, Illinois, 1972.

Louviere, J. and D. Street. Stated-Preference Methods. D.A. Hensher and K.J. Button eds. Handbook of Transport Modelling. Oxford: Pergamon (2001).

McFadden, D. “Economic Choices.” American Economic Review 91, (2001): 351-378.

Mayer, C. and T. Sinai. "Network Effects, Congestion Externalities, and Air Traffic Delays: Or Why Not All Delays are Evil.” American Economic Review 93, (2003): 1194-1215.

McCarthy, P.S. Transportation Economics-Theory and Practice: A Case Study Approach. Blackwell, Oxford, 2001.

McNally, M.G. “The Four-Step Model.” D.A. Hensher and K.J. Button eds. Handbook Of Transport Modelling. Oxford, Pergamon (2000).

Meyer, J.R., J.F. Kain, and M. Wohl. The Urban Transportation Problem, Harvard University Press, Cambridge, Massachusetts, 1965.

Meyer, J.R., M.J. Peck, J. Stenason, and C. Zwick. The Economics of Competition in the Transportation Industries. Harvard University Press, Cambridge, Massachusetts, 1959.

Mohring, H. and M. Harwitz. Highway Benefits. Northwestern University Press, Evanston, Illinois, 1962. 
Transportation Economics

Moore, T.G. "US Airline Deregulation; Its Effects on Passengers, Capital and Labor.” Journal of Law and Economics 29, (1986): 1-28.

Morrison, S.A. and C. Winston. The Economic Effects of Airline Deregulation. Brookings Institution, Washington, D.C., 1986.

Morrison, S.A. and C. Winston. "Empirical Implications and Tests of the Contestability Hypothesis.” Journal of Law and Economics 30, (1987): 53-66.

Moses, L.N. and H.F. Williamson. "Value of Time, Choice of Mode and the Subsidy Issue in Urban Transportation.” Journal of Political Economy 71, (1963): 247-264.

Munby, D. (ed.) Transport. Penguin, Harmondsworth, 1968.

Nelson, J.R. Marginal Cost Pricing in Practice. Prentice-Hall, Englewood Cliffs, New Jersey, 1964.

Newbery, D.M. "Pricing and Congestion: Economic Principles Relevant to Road Pricing.” Oxford Review of Economic Policy 6, (1990): 22-38.

Newbery, D.M.G. “Cost Recovery from Optimally Designed Roads.” Econometrica 56, (1989): 165-185.

Oum, T.H., W.G. Waters, and J.S. Yong. "Concepts of Price Elasticities of Transport Demand and Recent Empirical Evidence.” Journal of Transport Economics and Policy 26, (1992): 139-154.

Parry, I.W.H. and K.A. Small. “Does Britain or the U.S. Have the Right Gasoline Tax?” American Economic Review 95, (2005): 1276-1289.

Pegrum, D.F. Transportation: Economics and Public Policy $3^{\text {rd }}$ Ed. Richard D. Irwin, Homewood, Illinois, 1973.

Pels, E. and P. Rietveld. “Cost Functions in Transport.” D.A. Hensher and K.J. Button eds. Handbook of Transport Modelling. Oxford, Pergamon (2001).

Peltzman, S. “Towards a More General Theory of Regulation.” Journal of Law and Economics 19, (1976): 211-240.

Pirrong, S.C. “An Application of Core Theory to the Analysis of Ocean Shipping Markets.” Journal of Law and Economics 35, (1992): 89-131.

Porter, M.E. Competitive Advantage; Creating And Sustaining Superior Performance. Free Press, New York, New York, 1985.

Posner, R.A. “The Social Costs of Monopoly and Regulation.” Journal of Political Economy 83, (1975): 807-827.

Quandt, R.E. “Estimation of Modal Splits.” Transportation Research 2, (1976): 41-50.

Quandt, R.E. and W.J. Baumol. "The Demand for Abstract Transport Modes: Theory and Measurement.” Journal of Regional Science 6, (1966): 13-26.

Rassenti, S.J., V.L. Smith, and R.L. Bulfin. "A Combinational Auction Mechanism for Airport Time Slot Allocation.” Bell Journal of Economics 13, (1982): 369-384.

Robbins, L. Essays on the Nature and Significance of Economic Science. Macmillan, London, 1932.

Santos, G. and L. Rojey. "Distributional Implications of Road Pricing: The Truth Behind a Myth.” Transportation 31, (2003): 21-42.

Shepherd, W.G. “Contestability vs. Competition.” American Economics Review 74, (1984): 572587. 
Sjöstrom, W. “Collusion in Ocean Shipping: A Test of Monopoly and Empty Core Models.” Journal of Political Economy 97, (1989): 1160-1179.

Small, K.A. “Using the Revenue from Congestion Pricing.” Transportation 19, (1992): 359-381.

Small, K.A. and J.A. Gómez-Ibáñez. "Road Pricing for Congestion Management: The Transition from Theory to Policy.” K.J. Button and E.T. Verhoef eds. Road Pricing, Traffic Congestion and the Environment. Cheltenham: Edward Elgar (1998).

Starkie, D. “Road Indivisibilities: Some Observations.” Journal of Transport Economics and Policy. 16, (1982): 259-266.

Stigler, G.J. “The Theory of Economic Regulation.” Bell Journal of Economics and Management Science 2, (1971): 3-19.

Thibault, M. M. Brooks, and K.J. Button. "The Response of the U.S. Maritime Industry to the New Container Security Initiatives.” Transportation Journal 45, (2006): 5-15

Thomson, A.W. and L.C. Hunter. The Nationalized Transport Industries. Heineman, London, 1973.

Thomson, M. Modern Transport Economics. Penguin, Harmondsworth, 1974.

Tolifari, S., K.J. Button, and D. Pitfield. "Shipping Costs and the Controversy Over Open Registry." Journal of Industrial Economics 34, (1986): 409-427.

U.K. Ministry of Transport. Road Pricing: The Economic and Technical Possibilities. London, HMSO, 1964.

U.K. Ministry of Transport. Road Track Costs. London, HMSO, 1968.

Verhoef, E.T. The Economics of Road Pricing. Edward Elgar, Cheltenham, 1996.

Verhoef, E.T., P. Nijkamp, and P. Rietveld. "The Economics of Regulatory Parking Policies: The (Im)Possibilities of Parking Policies in Traffic Regulation." Transportation Research A 29, (1995): 141-156.

Vickrey, W.S. "Pricing in Urban and Suburban Transport.” American Economic Review 53, (1963): 452-465.

Vickrey, W.S. “Congestion Theory and Transport Investment.” American Economic Review 59, (1969): 251-260.

Walters A.A. "The Theory and Measurement of Private and Social Cost of Highway Congestion.” Econometrica 29, (1961): 676-697.

Wheaton, W.C. "Price-Induced Distortions on Urban Highway Investment." Bell Journal of Economics and Management Science 9, (1978): 622-632.

White, P.R. and S. Tough. “Alternative Tendering Systems and Deregulation in Britain.” Journal of Transport Economics and Policy 29, (1995): 275-289.

Winston, C. "Conceptual Developments in the Economics of Transportation: An Interpretive Survey.” Journal of Economic Literature 23, (1985): 57-94.

Winston, C. "Efficient Transport Infrastructure Policy." Journal of Economic Perspectives 5, (1991): 113-127. 
Transportation Economics

\section{Acknowledgments}

An earlier version of this paper was presented as the keynote address to the $38^{\text {th }}$ Universities Transport Study Group Annual Conference, Dublin, 2006. This is an expanded version of that talk that adds United States material to what was originally a paper intended for a United Kingdom and Irish audience. The UTSG is a purely academic organization that links the various transportation groups of all disciplines across the U.K. and Ireland. Its Web page is http://www.utsg.net

Kenneth Button is professor and director of the Center for Transportation Policy, Operations and Logistics in the School of Public Policy, George Mason University. He is also professor in civil engineering at the University of Porto and visiting professor in applied economics at the University of Bologna. He has held visiting posts at the University of British Columbia and the University of California at Berkley.

Dr. Button's training was in the fields of economics, econometrics and transportation planning. He has published, or has in press, some 90 books, more than 400 papers in leading academic journals, and forecasting software. He has given written and oral evidence to the U.S. Congress and to both the U.K. House of Lords and U.K. House of Commons Transport Committees. He is editor of the academic journals Transportation Research D: Transport and the Environment and Journal of Air Transport Management and is on the editorial boards of nine other journals. He is on the scientific committee of the World Conference on Transport Research and on the Committee of the Air Transportation Research Society. He has completed consultancy projects for the major international agencies (the World Bank, the Organisation for Economic Co-operation and Development, and the United Nations), for regional bodies (Asia-Pacific Economic Cooperation and the European Union), national governments and their agencies (the U.K., Italy, the Netherlands, Sweden, Canada, United States, Belgium, and Germany) and local governments as well as public and private companies. He is a recipient of the Transportation Research Forum Distinguished Researcher Award. 